УДК $322 ; 316.347$

МЕЖДУНАРОДНЫЕ МИГРАЦИИ КАК ФАКТОР СОЦИОКУЛЬТУРНОЙ ТРАНСФОРМАЦИИ ОБЩЕСТВ

\author{
Солодова Галина Сергеевна, \\ доктор сочиологических наук, \\ ведущий научный сотрудник Института философии и права СО РАН, \\ профессор кафедры сочиологии, политологии и психологии, \\ Сибирского государственного университета телекоммуникаций и информатики, \\ 2. Новосибирск
}

DOI: 10.31618/ESU.2413-9335.2019.6.61.49

\title{
INTERNATIONAL MIGRATIONS AS A FACTOR OF SOCIAL AND CULTURAL TRANSFORMATION OF SOCIETIES
}

Solodova Galina Sergeevna

Institute of Philosophy and Law of the

Siberian Branch of Russian Academy of Sciences,

АННОТАЦИЯ.

Siberian State University of Telecommunications and Information Sciences, Novosibirsk

Активизация международной миграции актуализирует проблемы регулирования межэтнических и межконфессиональных взаимодействий, социокультурных трансформаций в целом. Встает задача их типологизации и выработки моделей социального регулирования. Изучение механизма потенциальных социальных изменений предполагает рассмотрение того, насколько исходные культурные архетипы общества способствуют или, напротив, задерживают процессы социокультурных трансформаций.

\section{ABSTRACT}

Activation of international migration actualizes the problems of regulation of interethnic and interfaith interactions, socio-cultural transformations in general. There is a problem of their typologization and development of models of their social regulation. The study of the mechanism of social change implies consideration of how the original cultural archetypes of society can, or vice versa, delay the processes of sociocultural transformations.

Ключевые слова: социокультурные трансформации, международные миграции, межэтнические взаимодействия

Keywords: sociocultural transformations, international transportation, inter-ethnic interaction

Актуальность. Одним из проявлений процессов глобализации является интенсификация территориальных перемещений. К основным предпосылкам, способствующим расширению географии миграционных потоков, можно отнести следующие: во-первых, современное общество располагает техническими, транспортными возможностями для активных территориальных передвижений. Во-вторых, трансформация международных отношений социальные политика и условия большинства государств явно не препятствуют межгосударственным миграциям. Далее - изменения в экономической сфере, глобализация производства и расширение рынков труда. Вне зависимости от того, как мы воспринимаем глобализацию, сегодня мы живём в мире не обособленных обществ - культур и экономик, а в неком тесно переплетённом и взаимовлияющем пространстве.

В предшествующие десятилетия проблемы, обусловленные международной миграцией, стали в России, как и во многих регионах мира, политическим вопросом, вопросом государственной безопасности. Тема внешней миграции официально признана одним из политических приоритетов многих государства. В ее решение вовлечены не только специальные государственные структуры и аналитики, работающие в этой области, но и самый широкий круг политиков и экспертов, в том числе до недавнего времени весьма далеких от миграционной проблематики.

Основные подходы и результаты. Традиционно входя в сферу интересов демографов, сегодня тема миграции - предмет междисциплинарного изучения. В исследовании причин и последствий территориальных перемещений свою нишу находят политики, экономисты, социологи. Обращаясь к исторической ретроспективе, отметим, что основные положения и закономерности протекания международных миграционных процессов были предложены и сформулированы в конце XIX в. Е.Г. Равенштейном. В их основе лежит анализ миграции из Великобритании в Северную Америку. Были выявлены доминирование экономических причин, ориентированность на административно-территориальные центры, наличие возвратных процессов, тенденция возрастание интенсивности миграционных движений по мере развития экономики и транспорта.

Международная миграция это всегда внесение в принимающее общество новых элементов культуры, ценностей и повседневных практик. В данной статье акцент сделан на социокультурном видении проблемы, на культуре как детерминанте социокультурных трансформаций разных сфер общественной жизни, в том числе пространства межэтнических отношений. 
Целесообразность рассмотрения миграционных процессов в социокультурных рамках, обусловлена тем, что социокультурный подход позволяет рассмотреть социальные преобразования с позиций культурных традиций общества. К числу основных характеристик социокультурного подхода следует отнести возможность рассмотрения общества как цельного, единого, взаимозависимого, но несовпадающего в своих границах, пространства культуры и социального. Связь между личностью, обществом и культурой, по определению П. А. Сорокина являющихся «неразрывной триадой», достигается интернализацией индивидом культурных норм и императивов, принятых типов взаимодействия. Это служит одним из способов, обеспечивающих стабильность в сохранении культуры и общества. Одновременно индивид экстернализирует во внешнее социокультурное пространство усвоенные ценности и практики, которые, в свою очередь, могут приобретать индивидуальное преломление. Таким образом, он участвует в развитии и конструировании социокультурных процессов. Подобная схема является одной из иллюстраций и свидетельств связи личности, общества и культуры, что обусловливает исследовательское внимание к индивиду, с одной стороны, как к носителю и пользователю культурных и социальных норм, с другой, не только как к интернализирующему, но и как к экстернализирующему субъекту.

Социальные, общественные трансформации прерогатива не только сегодняшнего дня. Само наличие социальной истории свидетельствует о способности обществ к преобразованиям. В самой общественной природе заложен потенциал преобразующих изменений. Стремление и способность к изменениям являются имманентными свойствами и составными элементами социальных систем. Однако предрасположенность к изменениям в разных обществах неодинакова. Скорость, направление, глубина и успешность преобразований определяются исходными социокультурными условиями, открытостью и восприимчивостью общества к внешним и внутренним воздействиям. Иными словами, в основе социальных изменений - преимущественно объективные социокультурные основания, обеспечивающие разную результативность перемен.

Любое общество существует и изменяется в рамках большей или меньшей преемственности, сохранения и воспроизводства уже сложившихся социальных и культурных традиций и практик. Соответственно, всякая реальная и возможная трансформация является продуктом наложения конкретной социальной ситуации на традиционную культуру общества. Возможности трансформации в значительной степени ограничены и детерминированы исторически сложившимся менталитетом членов общества. Потенциал изменений и трансформаций, - пишет Ш.Н. Айзенштадт, - не является чем-то случайным или внешним по отношению к культуре. Он имплицитно присутствует во взаимодействии культуры и социальной структуры» $[1$, с. 208 209].
Помимо стремления к изменениям в любом обществе одновременно присутствует сдерживающая, «консервативная» тенденция, направленная на сохранение, воспроизводство и самовоспроизводство уже существующих институтов. Изучение механизма социальных изменений предполагает рассмотрение того, насколько исходные культурные архетипы общества и его социальная структура способствуют или, напротив, задерживают развитие изменений. Знание отправной, в определенном смысле базовой, социокультурной составляющей, оценка степени ее сохранения и влияния на скорость и направление переходных процессов служит необходимой предпосылкой для обеспечения результативности как текущих, так и долговременных трансформаций.

Социальные изменения, произошедшие в российском обществе и на постсоветском пространстве в предшествующие десятилетия, носят комплексный характер - наблюдаются перемены в структуре и организации его социальных институтов, образе мышления, поведении значительных групп населения. Пересматриваются ранее устойчивые социальные нормы, представления, исчезают одни социальные практики и институционализируются другие. Меняются официально и общественно признанные основания легитимации законность и респектабельность приобретают новые понятия. Кардинальные по сути, резкие по форме, сжатые и интенсивные по характеру - изменения оказались значимыми для большей части населения. Важным является то, что полное отторжение приоритетов предшествующего советского периода и определенная размытость новых создали некоторую сумятицу и растерянность. Переломность общего социального контекста обусловила противоречивость оценок, неуверенность в «правильном» понимании настоящего и прошлого. Отсутствие базовой, единой для всех групп общества ценностной системы ведет к ценностной маргинализации.

Вместе с тем, обществу для своего сохранения и функционирования в той или иной мере должны быть присущи элементы прошлого опыта, т.е. должно быть некоторое повторение, воспроизводство базовых структур. Даже очень глубокие изменения с необходимостью должны включать определенные элементы традиционности и преемственности. Это не означает «калькирования», обращения к застывшим, раз и навсегда заданным типам поведения, но предполагает наличие неких сквозных, стержневых представлений, ценностей, понятий, практик, связанных с природными, климатическими условиями жизни народа. Функцию трансляции основных социальных архетипов обычно выполняет культура - результат избирательного забывания и запоминания. При этом в наибольшей степени присутствует стремление к сохранению и воспроизводству, лишь тех социальных образцов и практик, которые укрепляют стабильность общества и способствуют его жизнеспособности. Принадлежность к культуре, включенность в некое 
культурное пространство - с большой вероятностью влечет за собой усвоение и трансляцию определенных ценностных и поведенческих моделей, способов восприятия, объяснения и изменения или неизменения реальности. Культура легитимирует определенные поведенческие практики, делает их социальными нормами и обеспечивает их интернализацию. Значение и даже прессинг культуры определяется не только тем, что она влияет на человеческое поведение и представления, но и тем, что культура включает в себя и контролирующие функции. Культура является долговременной, исторически сложившейся, передаваемой из поколения в поколение устойчивой системой приоритетов. Она не ограничивается только настоящим, но тесно связана со стереотипами сознания, нравственностью, социальными нормами, сформированными предыдущими поколениями и проявляющимися в непосредственной деятельности. Образцы, практики межэтнических отношений являются частью общей культуры народа, его менталитета.

Процессы глобализации и международной миграции, мобильности в самом широком ее понимании, включают перемещение больших групп людей в инокультурную среду, что обусловливает сосуществование на одной территории носителей, иногда совершенно различных и непохожих друг на друга, языков, верований, традиций. Современное общество - динамично изменяющееся, качественно новое состояние социума. Фоновое присутствие иного культурного, этнического и конфессионального контекста стало эмпирическим фактом социальной жизни. Соотношение и пропорции представителей разных народов, приобретают динамизм и неустойчивость. В успешности межкультурных контактов большую роль может играть общность или, напротив, разность культур. Это результат политических усилий и жизни многих поколений. Как и большинство других сфер, практики межэтнических отношений задаются исторической памятью и социальной реальностью.

Внешние, международные миграции для страны реципиента могут оказаться как культурным, экономическим и социальным ресурсом, так и источником социальной напряженности и конфликтогенности. Вектор потенциальных социокультурных трансформаций принимающих обществ зависит от целого набора факторов. Однако большую роль играют укорененность местной и ввозимой культур, степень приверженности своим традициям, готовность приезжих интегрироваться в социокультурное пространство принимающего общества.

На фоне постоянного обновления социального пространства социальные связи становятся менее продолжительными и более поверхностными. Происходит снижение традиционных способов сохранения общественной солидарности, актуализируется задача поддержания общегражданской идентичности [2, с. 56-62]. Формирование единой общегражданской идентичности, в политической терминологии - российской нации, предотвращает ситуацию разобщённого соседского проживания. Общегражданская идентичность - способ интеграции представителей разных культур на базе одной общегражданской культуры. Логично, если в основе общегражданской культуры будет лежать культура принимающего общества, имеющая длительную территориальную привязку, глубокие исторические корни. Формирование общегражданской идентичности не подразумевает аннулирование или нивелирование национальных особенностей, языков и культур. Однако они с необходимостью должны дополняться сквозной, связующей общество культурой, объединяющей все культуры разных народов. Формирование общегражданской идентичности необходимо как способ формирования общегосударственной солидарности, условие поддержания стабильности и согласия по ключевым ценностям. Возможно, оптимальным для полиэтничного общества, была бы одновременная включённость и в этнокультурное сообщество, как часть принимающего общества и в принимающее общество, как таковое, то есть сохранение этнической и приобретение общегражданской идентичности.

Заключение. Принимающее общество, как и сами мигранты, видят необходимость в регулировании миграционных процессов. Логично, если одной из современных теоретико-методологических задач станет разработка положений о зависимости направления, скорости и успешности происходящих и потенциальных социокультурных изменений принимающих обществ не только от текущих регулятивно-управленческих действий, но и от традиционных установок и практик местного и приезжего населения. Однако, в любом случае, данная тактическая задача подчинена более важной стратегической цели - сохранению гражданской солидарности общества в целом.

\section{Список литературы}

1. Шмуэль Н. Айзенштадт. Конструктивные элементы великих революций: культура. Социальная структура, история и человеческая деятельность. THESIS. Весна 1993. Том 2. Vol. 1. C. 208209.

2. Солодова Г.С., Щеклачева Т.В. Принимающее общество и иноэтничные мигранты - общее и отличное в представлениях и взглядах. Вестник Новосибирского государственного университета. 2014. T. 12. № 4. С. 56-62. 